\title{
As contribuições da síndrome de burnout para o déficit do trabalho da enfermagem: revisão integrativa da literatura
}

\author{
The contributions of burnout syndrome to the nursing work deficit: integrative literature \\ review
}

Las contribuciones del síndrome de burnout al déficit de trabajo de enfermería: revisión integrativa de la literatura

Breno de Souza Mota ${ }^{1 *}$, Silvana Nunes Figueiredo ${ }^{1}$, Daniella Souza Gama Siqueira ${ }^{1}$, Nataly Danielle Araújo Queiroz ${ }^{1}$, Theodora Maria de Paiva dos Santos².

\section{RESUMO}

Objetivo: Investigar a relação da síndrome de burnout e a sua influência no déficit do trabalho dos profissionais da enfermagem. Métodos: Trata-se de uma revisão integrativa de literatura. O levantamento de dados foi realizado durante o período correspondente aos meses de janeiro e maio de 2020, utilizando a Biblioteca Virtual em Saúde e incluindo a Base de Dados de Enfermagem (BDENF) e Literatura LatinoAmericana em Ciências da Saúde (LILACS), pesquisados os Descritores em Ciências da Saúde (DeCS) na combinação Esgotamento psicológico AND Enfermagem AND Trabalho, sendo encontrados 862 itens que, após a aplicação dos critérios de inclusão e exclusão, resultaram em nove artigos que compuseram o estudo. Resultados: A exaustão emocional, condições de trabalho, turnos e carga-horária foram consideradas desencadeadores do processo de desenvolvimento da síndrome de burnout nos profissionais da equipe de enfermagem, bem como o estresse e os estressores. Considerações finais: Logo, os profissionais da enfermagem sofrem diariamente com as condições de trabalho proporcionadas, desvalorização e condições estressoras que influencia diretamente na assistência prestada aos seus pacientes, além de favorecer o aparecimento da síndrome de burnout, mascarada pela falsa sensação de satisfação profissional.

Palavras-chave: Esgotamento psicológico, Enfermagem, Trabalho.

\begin{abstract}
Objective: To investigate the relationship of burnout syndrome and its influence on the work deficit of nursing professionals. Methods: This is an integrative literature review. The data collection was carried out during the period corresponding to the months of January and May 2020, using the Virtual Health Library and including the Nursing Database (BDENF) and Latin American Literature in Health Sciences (LILACS). Researched the Descriptors in Health Sciences (DeCS) in the combination Psychological burnout AND Nursing AND Work, being found 862 items that, after applying the inclusion and exclusion criteria, resulted in nine articles that comprised the study. Results: Emotional exhaustion, working conditions, shifts and workload were considered triggers of the process of development of burnout syndrome in nursing team professionals, as well as stress and stressors. Final considerations: Therefore, nursing professionals suffer daily due their provided working conditions, devaluation and stressful conditions that directly influences the care provided to their patients, besides favoring the onset of burnout syndrome, masked by the false feeling of professional satisfaction.
\end{abstract}

Keywords: Psychological burnout, Nursing, Work.

${ }^{1}$ Centro Universitário FAMETRO (CEUNI-FAMETRO), Manaus - AM.

*E-mail: brenosouzamota@gmail.com

2 Faculdade Estácio do Amazonas (ESTÁCIO), Manaus - AM.

SUBMETIDO EM: 6/2020

ACEITO EM: 7/2020

PUBLICADO EM: 10/2020 


\section{RESUMEN}

Objetivo: Investigar la relación del síndrome de agotamiento y su influencia en el déficit laboral de los profesionales de enfermería. Métodos: Esta es una revisión de la literatura integrativa. La recopilación de datos se llevó a cabo durante el período correspondiente a los meses de enero y mayo de 2020, utilizando la Biblioteca Virtual de Salud e incluyendo la Base de Datos de Enfermería (BDENF) y Literatura Latinoamericana en Ciencias de la Salud (LILACS), investigó los Descriptores en Ciencias de la Salud (DeCS) en la combinación Agotamiento Psicológico Y Enfermería Y Trabajo, encontrando 862 elementos que , después de aplicar los criterios de inclusión y exclusión, dio lugar a 9 artículos que componían el estudio. Resultados: El agotamiento emocional, las condiciones de trabajo, los turnos y la carga de trabajo se consideraron desencadenantes del proceso de desarrollo del síndrome de agotamiento en los profesionales del equipo de enfermería, así como el estrés y los factores estresantes. Consideraciones finales: Por lo tanto, los profesionales de enfermería sufren diariamente las condiciones de trabajo proporcionadas, la devaluación y las condiciones estresantes que influyen directamente en la atención prestada a sus pacientes, además de favorecer la aparición del síndrome de agotamiento, enmascarado por la falsa sensación de satisfacción profesional.

Palabras clave: Agotamiento psicológico, Enfermería, Trabajo.

\section{INTRODUÇÃO}

De acordo com o Ministério da Saúde (2019), a síndrome de burnout (SB) é vista como uma doença psicossomática causada por diversos fatores que envolvem o trabalho ou o meio de convivência do indivíduo, principalmente em ambientes altamente competitivos ou que demandam muita responsabilidade. Esta exacerbação de atividades é comum em profissionais que convivem em ambientes sob pressão, incluindo os da saúde (MS, 2019).

Na tradução literal do inglês, burnout significa "queimar por completo" ou "esgotar-se", e a sua primeira colocação surgiu na década de 70, quando o psicanalista norte-americano Herbert Freudenberger utilizou o termo para descrever o desgaste psicofísico de, primariamente, profissionais do cuidado envolvidos com o uso abusivo de drogas lícitas e ilícitas. A partir disso, fora definida como uma síndrome psicológica, dividida em três extensões: cansaço emocional, impessoalização (ou cinismo) e irrealização profissional (VIEIRA I e RUSSO JA, 2019).

Estas extensões foram mais bem compreendidas a partir da introdução de um instrumento para a identificação da síndrome. Desde então a SB passou a ser investigada em profissionais de diversas áreas de atuação, não apenas da saúde.

A escala diagnóstica Maslach Burnout Inventory (MBI) permitiu o início da questão epidemiológica e a investigação de fatores determinantes do problema, incluindo a relação com o trabalho e sua organização, tornando-se crucial o enfoque na autoavaliação (VIEIRA I e RUSSO JA, 2019).

Apesar de ser um distúrbio antigo, as informações acerca da epidemiologia da SB ainda são escassas. Recentemente a World Health Organization (WHO) inseriu o acometimento na $11^{\text {a }}$ Revisão da Classificação Internacional de Doenças (CID-11) como um fenômeno ocupacional (WHO, 2019). Atualmente a SB passou a ser considerada um problema de saúde pública, visto seus impactos nas questões econômicas (diminuição do rendimento dos trabalhadores acometidos) e mentais (levando à depressão ou ideações suicidas) (SILVA DSD, et al., 2015).

Em profissionais de saúde a doença se manifesta com maior frequência por vários fatores, principalmente por questões de contato direto com o paciente que envolvem sentimentos de afetividade, angústia e impotência (FERNANDES LS et al., 2018).

Por outro lado, estudos apontam que, mesmo sofrendo e vivenciando situações estressoras diárias, os trabalhadores da saúde acabam criando sentimento de resistência ou enfretamento, com a finalidade de reduzir ou amenizar o caos psicológico (SILVA-JUNIOR RF, et al., 2020). 
Entre o grupo de trabalhadores da saúde afetados, inclui-se prioritariamente os da enfermagem por diversos motivos: sobrecarga de trabalho, jornada diuturna duplicada, exigências, preocupações familiares, conflitos interpessoais, contato direto com o paciente da sua admissão à morte, baixa remuneração, desqualificação profissional, além da falta de autonomia e da tomada de decisões. Todas essas características estressoras somadas acarretam o desenvolvimento da falta de adesão às atividades propostas, diminuição da qualidade de vida e aumento do turnover profissional (FERNANDES LS, et al., 2018).

Ademais, o conhecimento sobre a SB é de fundamental importância, pois o distúrbio afeta principalmente na qualidade dos serviços prestados aos pacientes, acarretando na imagem e rendimento profissional, interferindo integralmente na instituição. O desgaste psicofísico acarreta diversos problemas de recursos humanos, pois aumenta o número de afastamentos, licenças e até mesmo ausência do profissional, acarretando na sobrecarga de outros trabalhadores e colegas de equipe, aumentado 0 risco de desenvolvimento da SB (DUTRA HS, et al., 2019). Tendo em vista o rendimento profissional e os fatores norteadores da SB presentes no cotidiano dos profissionais da enfermagem, este estudo teve como objetivo geral investigar a relação da síndrome de burnout e a sua influência no déficit do trabalho dos profissionais da enfermagem.

\section{MÉTODOS}

Trata-se de uma revisão integrativa da literatura, que utiliza a coleta de literaturas antigas, que tenham um grande potencial teórico e empírico, que auxiliam na prática da enfermagem baseada em evidências, realizada entre os meses de janeiro e maio de 2020 (SOUSA LMM, et al., 2017). Tendo como base a seguinte pergunta norteadora: quais as contribuições da síndrome de burnout para o déficit do trabalho da enfermagem?

Foram selecionados artigos nacionais e internacionais, nos idiomas português e inglês, publicados no período entre 2015 a 2020, utilizando os descritores "Esgotamento psicológico", "Enfermagem" e "Trabalho", de acordo com os Descritores em Ciências da Saúde (DeCS). Posteriormente, pesquisados nas seguintes bases de dados eletrônicas: Bases de Dados de Enfermagem (BDENF) e Literatura Latino-Americana em Ciências da Saúde (LILACS), por meio da Biblioteca Virtual em Saúde (BVS), na seguinte combinação booleana: Esgotamento psicológico AND Enfermagem AND Trabalho.

Para os critérios de inclusão e seleção, foi realizada a leitura dos títulos e resumos dos artigos que mais se aproximavam com o objetivo do estudo; nos de exclusão, foram retirados os artigos que estavam fora do período delimitado, não disponíveis completamente, livros, teses, dissertações, repetidos nas bases de dados e que não tinham relação com o tema proposto.

Foi realizada a leitura integral de todos os artigos que se enquadraram nos critérios de elegibilidade ou quando a leitura dos resumos se encontrava insuficiente para obtenção de dados que se aproximassem ao objetivo do estudo. Após isto, efetuada a análise, interpretação e síntese dos selecionados para serem incluídos. A revisão de todos os artigos foi realizada por meio de avaliação independente de dois autores. Em seguida, os resultados foram comparados ao objetivo de pesquisa, reduzindo o aparecimento de viés ou qualquer exclusão de estudos que se encaixariam no estudo em questão.

\section{RESULTADOS}

A pesquisa dos descritores nas bases de dados resultou em 862 publicações. Após a aplicação dos critérios de inclusão e exclusão, foram selecionados 25 artigos para leitura na íntegra e nove artigos para a composição deste estudo (Figura 1). Dos nove artigos, sete pertencem ao LILACS (sendo quatro em português e três em inglês) e dois ao BDENF (ambos em português), sendo a maioria publicado no Brasil.

Neste estudo não houve revista ou publicação dominante, mas tanto a Revista de Enfermagem da UFPE (2016 e 2018) quanto a Revista Latino-Americana de Enfermagem (2015 e 2018), repetem-se duas vezes. Outras revistas foram O público e o privado (2015), Arquivos Brasileiros de Psicologia (2016), Revista Gaúcha de Enfermagem (2017), Revista Brasileira de Ciências da Saúde (2019) e Revista Brasileira de Enfermagem (2019). Apenas no ano de 2020 que não foram encontradas publicações pertinentes ao objetivo do estudo e à pergunta norteadora. 
Figura 1 - Fluxograma das etapas da seleção dos artigos para a revisão.

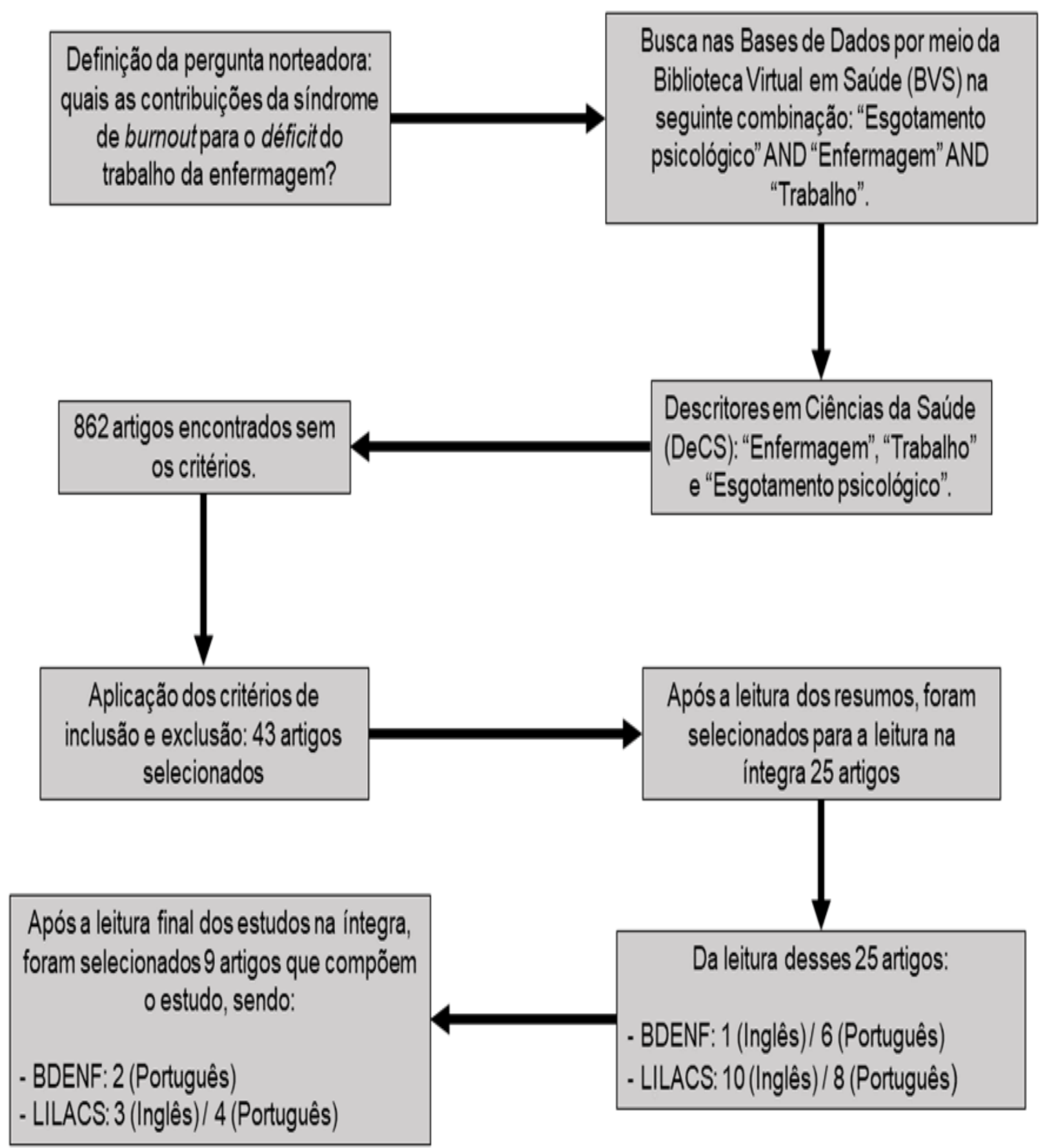

Fonte: MOTA BS, et al., 2020.

Em relação aos tipos de trabalho, dos nove artigos escolhidos para a composição desta revisão, sete tem como tipo de estudo o descritivo $(77,7 \%)$ e cinco do tipo transversal (55,5\%). Na abordagem, três são de natureza quantitativa $(33,3 \%)$, dois de qualitativa $(22,2 \%)$ e um de quanti-qualitativa $(11,1 \%)$. Sendo encontrados 4 resultados com um denominador comum (exaustão emocional) e cinco artigos com resultados divergentes e variantes.

Para melhor organização dos estudos selecionados, foram extraídas informações como autor, ano, título, objetivo, tipo de estudo, principais resultados e publicação, facilitando o processo de interpretação dos resultados obtidos e dos artigos selecionados para a composição do presente estudo (Quadro 1). Posteriormente, foram categorizados e agrupados em tópicos para melhor discussão e entendimento. 
Revista Eletrônica Acervo Saúde / Electronic Journal Collection Health ｜ ISSN 2178-2091

Quadro 1 - Artigos selecionados para a revisão integrativa, seguindo os enumerados, autor e ano, título, objetivo, estudo, principais resultados e publicação.

\begin{tabular}{|c|c|c|c|c|c|c|}
\hline № & Autor/Ano & Título & Objetivo & Estudo & Principais resultados & Publicação \\
\hline 1 & $\begin{array}{c}\text { Barrocas PHN, } \\
\text { et al. }(2015)\end{array}$ & $\begin{array}{l}\text { Condições de trabalho de } \\
\text { técnicas de enfermagem } \\
\text { de um hospital particular }\end{array}$ & $\begin{array}{l}\text { Identificar as condições de } \\
\text { trabalho de técnicas de } \\
\text { enfermagem e o impacto } \\
\text { para a saúde dessas } \\
\text { profissionais. }\end{array}$ & $\begin{array}{l}\text { Descritivo } \\
\text { com } \\
\text { abordagem } \\
\text { qualitativa }\end{array}$ & $\begin{array}{c}\text { Técnicas de enfermagem que } \\
\text { apresentaram níveis médios de Exaustão } \\
\text { Emocional (ao contrário das de níveis } \\
\text { altos) prestam um serviço mais } \\
\text { humanizado. }\end{array}$ & $\begin{array}{l}\text { O público e o } \\
\text { privado }\end{array}$ \\
\hline 2 & $\begin{array}{l}\text { Ramos CEB, } \\
\text { et al. (2019) }\end{array}$ & $\begin{array}{l}\text { Impactos da síndrome de } \\
\text { burnout na qualidade de } \\
\text { vida dos profissionais de } \\
\text { enfermagem da atenção } \\
\text { básica à saúde }\end{array}$ & $\begin{array}{l}\text { Identificar o impacto da } \\
\text { Síndrome de Burnout na } \\
\text { qualidade de vida dos } \\
\text { profissionais de enfermagem } \\
\text { da Atenção Básica à Saúde. }\end{array}$ & $\begin{array}{l}\text { Exploratório } \\
\text { e descritivo } \\
\text { com caráter } \\
\text { quanti- } \\
\text { qualitativo }\end{array}$ & $\begin{array}{l}\text { Profissionais de enfermagem mostraram } \\
\text { baixo índice de exaustão emocional (50\%) } \\
\text { e despersonalização ( } 51,9 \% \text { e alto nível } \\
\text { de realização profissional }(55,8 \%) .37,2 \% \\
\text { apresentaram cansaço mental. }\end{array}$ & $\begin{array}{l}\text { Revista } \\
\text { Brasileira de } \\
\text { Ciências da } \\
\text { Saúde }\end{array}$ \\
\hline 3 & $\begin{array}{l}\text { Vasconcelos } \\
\text { EM e Martino } \\
\text { MMF, (2017) }\end{array}$ & $\begin{array}{c}\text { Preditores da síndrome } \\
\text { de burnout em } \\
\text { enfermeiros de unidade } \\
\text { de terapia intensiva }\end{array}$ & $\begin{array}{l}\text { Identificar a prevalência e } \\
\text { analisar a existência de } \\
\text { fatores preditores da } \\
\text { síndrome de burnout em } \\
\text { enfermeiros de unidade de } \\
\text { terapia intensiva. }\end{array}$ & $\begin{array}{l}\text { Quantitativo, } \\
\text { descritivo e } \\
\text { transversal }\end{array}$ & $\begin{array}{l}\text { 14,3\% dos enfermeiros apresentaram a } \\
\text { síndrome de burnout. Tinham carga- } \\
\text { horária de } 30 / 40 \text { h semanais, trabalhavam } \\
\text { na terapia intensiva há } 2 / 3 \text { anos, não } \\
\text { participavam de capacitações e possuíam } \\
\text { férias de até } 25 \text { dias. }\end{array}$ & $\begin{array}{c}\text { Revista } \\
\text { Gaúcha de } \\
\text { Enfermagem }\end{array}$ \\
\hline 4 & $\begin{array}{l}\text { Pereira MMA e } \\
\text { Gomes ARS, } \\
(2016)\end{array}$ & $\begin{array}{l}\text { Stress, burnout e } \\
\text { avaliação cognitiva: um } \\
\text { estudo na classe de } \\
\text { enfermagem }\end{array}$ & $\begin{array}{l}\text { Avaliar aspectos psicológicos } \\
\text { do funcionamento de } \\
\text { profissionais enfermeiros e a } \\
\text { importância dos processos } \\
\text { de avaliação cognitiva. }\end{array}$ & $\begin{array}{l}\text { Transicional } \\
\text { cognitivo, } \\
\text { motivacional } \\
\text { e relacional } \\
\text { de Lazarus }\end{array}$ & $\begin{array}{l}\text { Os profissionais que apresentaram menor } \\
\text { enfrentamento do stress indicaram níveis } \\
\text { maiores de despersonalização e exaustão } \\
\text { emocional, com uma menor realização } \\
\text { profissional, além de sintomas de } \\
\text { depressão, o que influência na assistência. }\end{array}$ & $\begin{array}{l}\text { Arquivos } \\
\text { Brasileiros de } \\
\text { Psicologia }\end{array}$ \\
\hline 5 & $\begin{array}{l}\text { Trettene AS, } \\
\text { et al. (2016) }\end{array}$ & $\begin{array}{c}\text { Estresse em profissionais } \\
\text { de enfermagem atuantes } \\
\text { em um hospital } \\
\text { especializado }\end{array}$ & $\begin{array}{l}\text { Identificar o nível de estresse } \\
\text { dos profissionais de } \\
\text { enfermagem atuantes em um } \\
\text { hospital especializado. }\end{array}$ & $\begin{array}{l}\text { Transversal } \\
\text { com } \\
\text { delineamento } \\
\text { quantitativo }\end{array}$ & $\begin{array}{l}\text { Constatou que os profissionais da } \\
\text { enfermagem diagnosticados com estresse } \\
(28 \%) \text {, encontram-se na fase de } \\
\text { resistência (79\%) e aparecimento de } \\
\text { sintomas físicos (62\%), que quando } \\
\text { exacerbados, levam à exaustão. }\end{array}$ & $\begin{array}{l}\text { Revista de } \\
\text { Enfermagem } \\
\text { UFPE }\end{array}$ \\
\hline
\end{tabular}

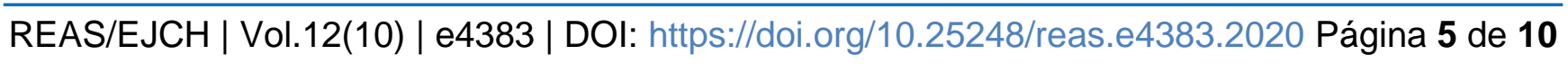




\begin{tabular}{|c|c|c|c|c|c|c|}
\hline № & Autor/Ano & Título & Objetivo & Estudo & Principais resultados & Publicação \\
\hline 6 & $\begin{array}{l}\text { Moreno JK, et } \\
\text { al. (2018) }\end{array}$ & $\begin{array}{c}\text { Síndrome de Burnout e } \\
\text { fatores de estresse em } \\
\text { enfermeiros } \\
\text { nefrologistas }\end{array}$ & $\begin{array}{l}\text { Identificar os riscos da } \\
\text { Síndrome de Burnout e } \\
\text { fatores de estresse em } \\
\text { enfermeiros nefrologistas. }\end{array}$ & $\begin{array}{l}\text { Qualitativo e } \\
\text { descritivo }\end{array}$ & $\begin{array}{c}\text { A sobrecarga de trabalho, o cumprimento de } \\
\text { atividades não pertinentes aos enfermeiros. O } \\
\text { esgotamento físico e psicológico é relatado } \\
\text { pelos profissionais que se sentem realizados } \\
\text { profissionalmente, porém assumem que o } \\
\text { cansaço pode interferir nas relações } \\
\text { interpessoais. }\end{array}$ & $\begin{array}{l}\text { Revista de } \\
\text { Enfermagem } \\
\text { UFPE }\end{array}$ \\
\hline 7 & $\begin{array}{l}\text { Nobre DFR, } \\
\text { et al. (2019) }\end{array}$ & $\begin{array}{l}\text { Burnout assessment in } \\
\text { nurses from a general } \\
\text { emergency service }\end{array}$ & $\begin{array}{l}\text { Avaliar o nível de Burnout } \\
\text { dos enfermeiros de um } \\
\text { serviço de urgência geral. }\end{array}$ & $\begin{array}{l}\text { Quantitativo, } \\
\text { descritivo, } \\
\text { correlacional e } \\
\text { transversal }\end{array}$ & $\begin{array}{c}\text { O Burnout foi dividido em três categorias: } \\
\text { pessoal }(51,4 \%) \text {, relacionado com o trabalho } \\
(58,5 \%) \text { e relacionado com o cliente }(53,1 \%) \text {. } \\
\text { O valor médio do Burnout apresentou um nível } \\
\text { elevado de } 54,33 \% .78,1 \% \text { dos enfermeiros no } \\
\text { estudo apresentaram Burnout total. } 53,1 \% \text { dos } \\
\text { enfermeiros referem desejo em mudar de } \\
\text { profissão. }\end{array}$ & $\begin{array}{l}\text { Revista } \\
\text { Brasileira de } \\
\text { Enfermagem }\end{array}$ \\
\hline 8 & $\begin{array}{l}\text { Vidotti V, et } \\
\text { al. (2018) }\end{array}$ & $\begin{array}{c}\text { Burnout Syndrome and } \\
\text { shift work among the } \\
\text { nursing staff }\end{array}$ & $\begin{array}{l}\text { Analisar os fatores os } \\
\text { fatores associados à } \\
\text { síndrome de Burnout, } \\
\text { segundo o turno de } \\
\text { trabalho da equipe de } \\
\text { enfermagem. }\end{array}$ & $\begin{array}{c}\text { Transversal e } \\
\text { descritivo }\end{array}$ & $\begin{array}{l}\text { Trabalhadores da enfermagem do turno diurno } \\
\text { apresentaram índices maiores de síndrome de } \\
\text { burnout. Exaustão emocional aumentada em } \\
\text { profissionais do turno noturno. Baixa } \\
\text { realização profissional aliada ao sedentarismo. } \\
\text { Baixo apoio social e sono prejudicado. }\end{array}$ & $\begin{array}{l}\text { Revista Latino- } \\
\text { Americana de } \\
\text { Enfermagem }\end{array}$ \\
\hline 9 & $\begin{array}{l}\text { Cruz SP e } \\
\text { Abellán MV, } \\
\text { (2015) }\end{array}$ & $\begin{array}{l}\text { Professional burnout, } \\
\text { stress and job } \\
\text { satisfaction of nursing } \\
\text { staff at a university } \\
\text { hospital }\end{array}$ & $\begin{array}{l}\text { Descrever as } \\
\text { características sócio- } \\
\text { ocupacionais do pessoal } \\
\text { de enfermagem de um } \\
\text { hospital terciário do } \\
\text { Serviço Público de Saúde } \\
\text { de Andalucía }\end{array}$ & $\begin{array}{l}\text { Observacional, } \\
\text { descritivo e } \\
\text { transversal }\end{array}$ & $\begin{array}{l}\text { Os níveis de exaustão emocional } \\
\text { apresentaram-se maiores nos profissionais } \\
\text { que não eram preceptores ( } 4.74 \text { pontos). A } \\
\text { realização profissional era gradativamente } \\
\text { aumentada em } 0.22 \text { pontos de acordo com a } \\
\text { idade do participante. }\end{array}$ & $\begin{array}{l}\text { Revista Latino- } \\
\text { Americana de } \\
\text { Enfermagem }\end{array}$ \\
\hline
\end{tabular}

Fonte: MOTA BS, et al., 2020.

REAS/EJCH | Vol.12(10) | e4383 | DOI: https://doi.org/10.25248/reas.e4383.2020 Página 6 de 10 


\section{DISCUSSÃO}

O interesse da publicação de artigos com a abordagem da SB mostrou-se bem lento ao longo dos anos selecionados para a coleta de dados da pesquisa. Apesar de ser uma doença que acomete a maioria dos profissionais de saúde (não somente da enfermagem), poucos se sentem interessados na discussão, pois estão satisfeitos com o seu trabalho, mesmo que por muito tempo a categoria tenha buscado pela sua valorização profissional, com exigências na mudança da carga-horária de trabalho e piso salarial, recentemente discutido pela pelo Projeto de Lei ํㅡㄹ 2564/2020.

\section{A satisfação profissional como apaziguadora do esgotamento psicológico}

Embora a satisfação profissional mostrada nos resultados seja um ponto que apoie a ideia de suportar a síndrome, os profissionais de enfermagem estão incluídos em uma categoria que sofre desvalorização, com salários reduzidos e sobrecarga de trabalho. A desvalorização e a não percepção do reconhecimento da enfermagem é uma luta constante travada desde os primórdios da profissão.

Pouco se discute sobre a valorização da profissão, ocupando um lugar no obscuro, sendo deixada de lado ou até mesmo não entrando em relevância em discussões multiprofissionais. A falta de reconhecimento implica diretamente na dinâmica do profissional, acarretando em frustrações ou até mesmo na diminuição da sua força de trabalho e efetivação do cuidado (LAGE CEB e ALVES MS, 2016).

Apesar do trabalho ser uma excelente fonte de satisfação pessoal, como a autorrealização, a exposição a riscos pode levar ao desencadeamento de diversas patologias, principalmente as mentais, como a SB. Diversos estudos apontam um crescimento significativo da relação profissão-síndrome que paulatinamente cresce, afetando na qualidade da assistência prestada, sendo sentida pelos clientes e assistidos (NOBRE DFR, et al., 2019).

A busca pela satisfação profissional exacerbada acarreta o desenvolvimento não apenas da SB, mas de diversas doenças psicossomáticas advindas da cobrança excessiva pela sociedade, pela constante rotatividade de profissionais da enfermagem no mercado e também por fatores advindos das condições de trabalho em que estão inseridos.

\section{A relação estresse, SB e o trabalho da enfermagem}

Todavia, o estresse mostrou-se um dos fatores que se associavam às questões do trabalho, pois envolverse em um ambiente que oferece riscos ocupacionais e ainda estar na linha de frente do atendimento, demanda muito esforço físico e psicológico.

O estresse é visto como uma reação fisiológica a alguma ameaça ou situação de perigo em que somos expostos, sendo desencadeada por estressores e colocando o organismo em estado de alerta, alterando o emocional e o físico do indivíduo (BVS, 2015). Urbanetto JS et al. (2019), descrevem que as características do estresse podem ser observadas diariamente e a variedade de estressores presentes podem variar substancialmente, desencadeando agravos à saúde.

Rivas E Barraza-Macias A (2018) discutem que o estresse laboral na equipe de enfermagem é comum, devido a todas as suas variáveis e determinantes. Dupla jornada de trabalho, exposição a riscos, cobranças da equipe e diminuição do seu tempo de lazer.

O estresse expressado de forma contínua e persistente, aliado a todos os fatores supracitados, podem gerar o desenvolvimento da SB. Vale ressaltar que o desenvolvimento da doença é multifatorial, que se origina desde uma cobrança excessiva até a percepção de estressores no ambiente de trabalho.

Em um estudo realizado em um hospital geral da Bahia, auxiliares, técnicos de enfermagem e enfermeiros relataram ter uma alta exigência de trabalho, principalmente dos setores de cuidado direto ao paciente. A equipe de enfermagem que trabalhava no setor administrativo relatou sentir menor exigência no trabalho efetuado, fora a insatisfação do apoio dos seus superiores em questões trabalhistas, relatada por mais de $50 \%$ dos entrevistados no estudo (AZEVEDO BDS, et al., 2017). O descuido com a enfermagem procede desde a chefia, disseminando desinteresse em seus subordinados, levando ao desinteresse para com a categoria. 


\section{As condições trabalhistas da enfermagem e a sua relação com a SB}

Entretanto, outro fator que influencia no aparecimento dos sintomas da SB é justamente a carga-horária de trabalho, que se diferencia entre 30 a 40 horas semanais. Em uma pesquisa, o tempo trabalhado variava de 44 horas para técnicos e 24 horas semanais para enfermeiros do serviço móvel de urgência entrevistados, mas devido à jornada dupla, esse valor chegou a ser de 81 a 100 horas semanais de trabalho (SILVA FG, et al., 2019).

A carga-horária de trabalho, apesar de ser pouco discutida, acarreta problemas no sono e também no acúmulo de trabalho, por outro lado, interfere precisamente na renda (quantos mais horas trabalhadas, maior será o salário, na maioria dos casos).

Em relação ao turno de trabalho, uma revisão de literatura demonstra a prevalência de estudos que comprovam o aparecimento de predisposição à SB em profissionais do período noturno, porém neste estudo os índices de SB foram superiores no turno diurno, contudo a exaustão emocional foi aumentada no turno noturno, além da baixa realização profissional, sedentarismo e sono prejudicado (OLIVEIRA RF, et al., 2017).

O turno de trabalho noturno tem consequências irreversíveis à saúde, pois o sono é um processo que revitaliza as energias do corpo, mantendo-o preparado para mais um dia. Entretanto, sabe-se que o sono tem ações diretas no cansaço mental e na acuidade das atividades exercidas pelos profissionais.

O cansaço mental aliado a sobrecarga de trabalho afeta na qualidade da assistência de enfermagem prestada. Em uma revisão de natureza qualitativa, não apenas os fatores supracitados influenciam, também como a insegurança na execução dos serviços ao paciente, bem como a falta de educação continuada e atualizações pertinentes à área de atuação e também a sensação de impotência, aliada à frustração, que culminam em um nível elevado de estresse, corroborando com a resistência ao desgaste psicológico (VALERETTO FA e ALVES DF, 2013).

A SB corresponde a sobrecarga do trabalho devido a todas as situações estressoras ou que vão além da sua capacidade de trabalho e que afeta de forma negativa principalmente o rendimento do profissional, a sua relação com o trabalho e a organização das ações, colocando a saúde e a vida do acometido em risco (AZEVEDO KCC, et al., 2019). Isso influencia diretamente na eficiência do trabalho, podendo culminar em desatenção ou prejudicar seu rendimento durante todas as atividades prestadas, muitas vezes despercebida pela profissional logo no início, gerando o atraso na identificação dos sintomas.

Nos artigos encontrados para esta revisão, o aparecimento dos sintomas acaba sendo tardio, devido à resistência dos profissionais ao estresse, gerado pela sensação de realização profissional. Porém, sintomas físicos acabam sendo mais comuns antes da exaustão emocional (um dos indicadores pesquisados para 0 diagnóstico clínico).

Batista $\mathrm{KO}$ et al. (2019) discutem o desleixo dos trabalhadores da enfermagem com a própria saúde e o lazer, além da sua influência no atendimento e qualidade do serviço. O comprometimento exacerbado com o trabalho acaba excluindo o profissional das suas atividades de descontração ou entretenimento, dedicando sua vida inteiramente ao trabalho, além do desenvolvimento de outras patologias que podem aparecer de maneira rápida ou tardia, dependendo da percepção do profissional frente à doença.

Em um outro estudo, realizado com 82 profissionais de enfermagem que trabalham em Unidades de Pronto Atendimento, foi relacionado a autoeficácia e as dimensões que se correlacionam com burnout, como a exaustão emocional.

Profissionais que se sentiam seguros na sua assistência, eram competentes e estavam atualizados ou realizavam boas práticas no serviço, acabavam se sentindo menos exaustos emocionalmente, consequentemente, menos insatisfeitos com a sua profissão (LOIOLA E MARTINS MC, 2019).

Isto corrobora com a relação da exaustão emocional e a assistência prestada, apresentada nos resultados da pesquisa, que mostra que mais de $50 \%$ dos profissionais sentiram ou sentem o desejo de mudar de profissão, bem como a presença da SB em mais de $70 \%$ dos entrevistados. 


\section{A resiliência e 0 apoio social}

Silva SM et al. (2016) dizem que outro fator culminante na diminuição do estresse, resultando em menores chances do desenvolvimento da SB, foi a resiliência, mensurada por meio da Escala de Resiliência que possui 25 itens descritos, com pontuações de 1 a 7 , podendo ser inferido um valor que pode variar entre 25 a 175 de escore. Quanto mais altos os índices de resiliência, menor a exaustão emocional (8\%) e maior a realização pessoal/profissional (26\%). Os níveis de resiliência influenciam diretamente nas relações interpessoais e no trabalho da enfermagem, ao mesmo passo que resultam em altos índices de satisfação profissional. A resiliência no ambiente de trabalho facilita a interação e a capacidade de se reconstituir e ir em busca de melhorias, visando a qualidade do atendimento e do serviço prestado, importante para a categoria e atuação profissional.

Outro fator de relevância é o apoio social, pois o apoio de familiares, gestores e sociedade com a profissão é importante para que haja melhor compreensão do papel profissional e o respeito do seu espaço, além da luta pela valorização. Tanto que é considerado uma ferramenta importante para o enfrentamento do estresse, pois auxilia no entendimento de problemas e na adoção de um estilo de vida mais saudável. Este fator pode ser visto desde a academia, pois um estudo transversal, de abordagem quantitativa, realizado em uma universidade pública do interior de São Paulo, identificou que o apoio social gera impactos na vida do acadêmico que podem partir para a formação profissional, formando profissionais questionadores da sua profissão, como bem visto na insatisfação profissional abordada nos resultados deste estudo (ALMEIDA LY, et al., 2018).

\section{Estratégias que podem reduzir a SB nos profissionais de enfermagem}

Embora os artigos encontrados nesta revisão englobem os principais problemas enfrentados pela equipe de enfermagem e os fatores que levam ao desenvolvimento da SB em trabalhadores da equipe de enfermagem, existem estratégias que, quando bem aplicados, auxiliam na redução do estresse e auxiliam na redução deste acometimento.

Lopes LS et al. (2019) realizaram uma oficina de yoga para funcionários da equipe de enfermagem de um setor de oncologia de um hospital, os profissionais foram submetidos a questionários antes e após as sessões que resultaram em uma resposta satisfatória e benéfica dos indicadores de estresse, ansiedade, depressão e enfrentamento dos estressores ocupacionais, que foram discutidos durante todo este trabalho como fatores que favorecem o desenvolvimento da síndrome de burnout. Logo, a implementação de atividades de relaxamento, mindfulness, exercícios de respiração ou rodas de conversa que reúnam experiências, levantem questões de trabalho e discutam mais sobre o acometimento.

\section{CONSIDERAÇÕES FINAIS}

O trabalho da enfermagem é de extrema importância na saúde, pois exige contato direto com o paciente, tendo a necessidade do acompanhamento de todas as questões psicossociais do cliente, de sua família e comunidade. A somatória desses fatores, junto à desvalorização, sobrecarga de trabalho, altos índices de estresse, exposição a riscos e baixa qualidade de vida, expõe os profissionais da equipe de enfermagem aos desencadeadores e aparecimentos dos sintomas da SB. Porém, conforme o levantamento realizado nesta revisão, o alto índice de satisfação com o trabalho, de alguma forma, omite o aparecimento da SB na sua forma aguda, levando à cronicidade e ao desgaste psicológico avançado. Logo, o acompanhamento psicológico, valorizando a saúde mental dos profissionais da saúde é válido, pois a identificação precoce da síndrome previne uma futura queixa que influencie diretamente no trabalho. Ressalta-se que as buscas por novas formas de diagnóstico do agravo devem ser implementadas nos serviços de saúde, não apenas para profissionais da equipe de enfermagem, mas também para os que compõem a equipe multiprofissional. Além disso, quanto mais capacitações e atualizações o profissional tiver, melhor será seu rendimento, reconhecimento e dedicação ao serviço prestado.

\section{REFERÊNCIAS}

1. ALMEIDA LY, et. al. Avaliação do apoio social e estresse em estudantes de enfermagem. Rev Esc Enferm USP, 2018; 52: e03404. 
2. AZEVEDO BDS, et al. Estresse ocupacional e insatisfação com a qualidade de vida no trabalho da enfermagem. Texto Contexto Enferm, 2017; 26(1): e3940015.

3. AZEVEDO KCC, et al. National scientific production on Burnout Syndrome in ICU nurses and physicians: a bibliometric study. Rev Assoc Med Bras, 2019; 65(5): 722-729.

4. BARROCAS PHN, et al. Condições de trabalho de técnicas de enfermagem de um hospital particular. O público e o privado, 2015; nำ 25: 77-100.

5. BATISTA KO, et al. Síndrome de burnout em enfermeiros: consequências na atividade profissional. ReBIS, 2019; 1(4): 61-65.

6. BRASIL, MINISTÉRIO DA SAÚDE. Agenda de Ações Estratégicas para a Vigilância e Prevenção do Suicídio e Promoção da Saúde no Brasil: 2017 a 2020. Brasília: Ministério da Saúde, 2017; 34p.

7. CRUZ SP, ABELLÁN MV. Desgaste profissional, stress e satisfação no trabalho do pessoal de enfermagem em um hospital universitário. Rev. Latino-Am. Enfermagem, 2015; 23(3): 543-552.

8. DUTRA HS, et al. Burnout entre profissionais de enfermagem em hospitais no Brasil. Rev. Cuid., 2019; $10(1)$ : e585.

9. FERNANDES LS, et al. Associação entre Síndrome de burnout, uso prejudicial de álcool e tabagismo na Enfermagem nas UTIs de um hospital universitário. Ciência e Saúde coletiva, 2018; 23(1): 203-214.

10. LAGE CEB, ALVES MS. (Des)valorização da enfermagem: implicações no cotidiano do enfermeiro. Enferm. Foco, $2016 ; 7(3 / 4): 12-16$.

11. LOIOLA E, MARTINS MC. Autoeficácia no trabalho e síndrome de burnout em profissionais de enfermagem. Psicologia, Saúde \& Doenças, 2019; 20(3): 813-823.

12. LOPES LS, et al. Yoga para Manejo e Redução da Síndrome de Burnout em Profissionais da Saúde. Rev Bras Terap e Saúde, 2019; 9(2): 1-7.

13. MORENO JK, et al. Síndrome de burnout e fatores de estresse em enfermeiros nefrologistas. Rev Enferm UFPE, 2018; 12(4): 865-871.

14. MOURA RS, et al. Estresse, burnout e depressão nos auxiliares e técnicos em enfermagem das unidades de terapia intensiva. Enfermería global, 2019; nº 54: 94-108.

15. NOBRE DFR, et al. Avaliação do burnout em enfermeiros de um serviço de urgência geral. Rev Bras Enferm, 2019; 72(6): 1533-9.

16. OLIVEIRA RF, et al. Incidência da síndrome de burnout nos profissionais de enfermagem: uma revisão integrativa. Revista de Enfermagem do Centro-Oeste Mineiro, 2017; 7: e1383.

17. PEREIRA MMA, GOMES ARS. Stress, burnout e avaliação cognitiva: estudo na classe de enfermagem. Arquivos Brasileiros de Psicologia, 2016; 68(1): 72-83.

18. RAMOS CEB, et al. Impactos da síndrome de burnout na qualidade de vida dos profissionais de enfermagem da atenção básica à saúde. R bras ci Saúde, 2019; 23(3): 285-296.

19. RIVAS E, BARRAZA-MACÍAS A. Síndrome de Burnout no pessoal de enfermagem e sua relação com quatro variáveis laborais. Enfermería Universitaria, 2018; 15(2): 136-146.

20. SANCLEMENTE-VINUE I, et al. A voz da enfermagem como ferramenta para promover o engagement no trabalho. Rev. Latino-Am. Enfermagem, 2019; 27: e3208.

21. SILVA DSD, et al. Depressão e risco de suicídio entre profissionais de Enfermagem: revisão integrativa. Rev Esc Enferm USP, 2015; 49(6): 1027-1036.

22. SILVA SM, et al. Relação entre resiliência e burnout: promoção da saúde mental e ocupacional dos enfermeiros. Revista Portuguesa de Enfermagem de Saúde Mental, 2016; nº 16: 41-48.

23. SILVA FG, et al. Predisposição para síndrome de burnout na equipe de enfermagem do serviço de atendimento móvel de urgência. Enferm. Foco, 2019; 10(1): 40-45.

24. SILVA-JUNIOR RF, et al. Personalidade hardiness e fatores associados em profissionais da saúde atuantes em serviços que atendem pacientes críticos. Ciência \& Saúde Coletiva, 2020; 25(1): 199-209.

25. SOUSA LMM, et al. A metodologia de revisão integrativa da literatura em enfermagem. Revista Investigação em Enfermagem, 2017; 17-26.

26. TRETTENE AS, et al. Estresse em profissionais de enfermagem atuantes em um hospital especializado. Rev Enferm UFPE, 2016; 10(12): 4450-4458.

27. URBANETTO JS, et al. Estresse e sobrepeso/obesidade em estudantes de enfermagem. Rev. Latino-Am. Enfermagem, 2019; 27: e3177.

28. VALERETTO FA, ALVES DF. Fatores desencadeantes do estresse ocupacional e da síndrome de burnout em enfermeiros. Revista Saúde Física \& Mental, UNIABEU. 2013; 3(2): 1-11.

29. VASCONCELOS EM, MARTINO MMF. Preditores da síndrome de burnout em enfermeiros de unidade de terapia intensiva. Rev Gaúcha Enferm., 2017; 38(4): e65354.

30. VIDOTTI V, et al. Síndrome de Burnout e o trabalho em turnos na equipe de enfermagem. Rev. Latino-Am. Enfermagem, 2018; 26: e3022.

31. VIDOTTI V, et al. Síndrome de burnout, estresse ocupacional e qualidade de vida. Enfermería Global, 2019; nº 55: 355-365.

32. VIEIRA I, RUSSO J. Burnout e estresse: entre medicalização e psicologização. Revista de Saúde Coletiva, 2019; 29(2): e290206.

33. WHO. Suicide in the world: Global Health Estimates. World Health Organization, 2019. 